Original Research Paper

\title{
The Association of HLA Class II Alleles with the Response to Alfa-Interferon/Ribavirin Therapy in Chronic Hepatitis $\mathrm{C}$ Patients
}

\author{
${ }^{1}$ Awny Aly Abol-Ez Gawish, ${ }^{1}$ Nahla Abd El-Hamid Mohammed, \\ ${ }^{1}$ Rasha Adel Sayed Ahmed Hussein and ${ }^{2}$ Elsaid Galal El-Badrawy \\ ${ }^{I}$ Department of Medical Microbiology and Immunology, Faculty of Medicine, Zagazig University, Egypt \\ ${ }^{2}$ Department of Tropical medicine, Faculty of Medicine, Zagazig University, Egypt
}

Article history

Received: 28-05-2015

Revised: $14-08-2015$

Accepted: 08-09-2015

Corresponding Author:

Rasha Adel Sayed Ahmed Hussein Department of Medical

Microbiology and Immunology,

Faculty of Medicine,

Zagazig University, Egypt

Email: rahessin1981@gmail.com

\begin{abstract}
Human Leucocyte Antigens (HLA) class II appears to play an important role in the individual's immune response to viral infection. The present study was aimed at assessment of the relationship between HLA DRB1 alleles and the response to HCV combined therapy in Chronic Hepatitis $\mathrm{C}$ patients (CHC). We enrolled a total of 44 chronically infected HCV patients without Hepatitis B Virus (HBV) or Human Immunodeficiency Virus (HIV). Their mean age was $36.45 \pm 11.18$ years (21-63). HLA-DRB1 typing was done by real time Polymerase Chain Reaction (PCR). ALT and Hemoglobin ( $\mathrm{Hb}$ ) levels were assessed as well as viral genotype was taken from patients' reports ( $\mathrm{HCV}$ genotypes were $1,2,3$ and 4 representing $13.6,13.6,4.5$ and $68.18 \%$, respectively). The most frequent alleles demonstrated among patients were DRB $1 * 13$ and DRB1*07 (31.8 and 36.4\%, respectively). Analysis of DRB1 frequency between sustained responders and non responders revealed that DRB $1 * 13$ allele was significantly higher among sustained responders $(p<0.001)$, while DRB $1 * 07$ allele was significantly higher among non responders $(p<0.01)$. Female sex, HCV genotype 2 and pretreatment low serum HCV RNA level were associated with Sustained Virological Response (SVR). Also, elevated Alanine aminotransferase (ALT) level at the 1st week of therapy followed by return to baseline level at the 4th week and a decrease of the mean hemoglobin concentration at 4 th week and 12th week of therapy were significantly associated with SVR. We concluded that the virological and special HLA patterns may possibly predict the response to combination therapy in $\mathrm{CHC}$ patients.
\end{abstract}

Keywords: Hepatitis C, Pegylated Interferon, Ribavirin, Human Leukocyte Antigen, Sustained Virological Response

\section{Introduction}

The World Health Organization (WHO) has declared hepatitis $\mathrm{C}$ a global health problem, with approximately $3 \%$ of the world's population infected with the Hepatitis $\mathrm{C}$ Virus (HCV). There are more than 170 million HCV chronic carriers at risk of developing liver cirrhosis andor Hepatocellular Carcinoma (HCC) (Mosaad et al., 2010). Egypt has approximately $13 \%$ (about 10 millions) anti-HCV positive individuals mainly genotype 4a (Elkady et al., 2009).
Combination therapy with Pegylated Interferonalpha (Peg-IFN) and ribavirin has been recommended and approved for patients with $\mathrm{HCV}$ infection (El Makhzangy et al., 2009). Although new era of treatment of hepatitis $\mathrm{C}$ are used in other countries, in Egypt under supervision of the National Committee for the Control of Viral Hepatitis (NCCVH) interferon still has been used plus ribavirin with added a new antiviral drug called Sofosbuvir to form triple therapy since October 2014 (NCCVH, 2014). So interferon and ribavirin are essential in treatment of hepatitis $\mathrm{C}$ 
in Egypt. The goal of antiviral therapy is to achieve viral eradication. Clinically, therapeutic success is known as a Sustained Virologic Response (SVR), defined as undetectable serum HCV RNA for at least 6 months after cessation of therapy, thereby resolving liver inflammation and the progression to cirrhosis and hepatocellular carcinoma (Maylin et al., 2008). Treatment is costly and causes many side effects (Bhatti and Berenson, 2007). Also not all patients who receive antiviral therapy are able to clear the virus and respond to treatment; only about $55 \%$ of patients can successfully clear the virus depending on virological factors and host factors including immunogenetic factors (Dai et al., 2010).

The viral genotype, one of the most important viral predictors, has become the critical determinant of the length of combination therapy. On the other hand, some host factors such as age, gender, race, insulin resistance and host immune responses may also significantly affect drug response (Alberti and Benvegnù, 2003; Dai et al., 2009). Polymorphisms of the genes that regulate the immunity and the genes of Human Leukocyte Antigen (HLA) class I and II molecules are known to affect the clearance or persistence of viral antigens (Ocal et al., 2014). It was reported that HLA class II alleles, particularly DRB1 and DQB1 alleles, play a critical role in the outcome of $\mathrm{HCV}$ infection, influence susceptibility to or protection from $\mathrm{HCV}$ infection and also affect response to antiviral treatment (Shaker et al., 2013).

To our knowledge, HLA-associated alleles in Egyptian patients with hepatitis $\mathrm{C}$ have been studied using current methods include Sequence-Specific Oligonucleotide Probe Hybridization (SSOPH), Sequence-Specific Primers (SSP) and PCR-SSO luminex technology which are costly and require multiple steps (Shaker et al., 2013; Shaheen et al., 2013; Yosry et al., 2011).

In this study, we tried to assess the association between HLA class II (DRB1) alleles and response to combined interferon alpha and ribavirin therapy in $\mathrm{HCV}$ infected Egyptian patients, to investigate whether these alleles could be useful as predictors to treatment response, using a recent promising technology for HLA typing, (real time PCR) that has many advantages over other HLA typing methods. The primers for the allele-specific amplification and the internal control are mixed together in one well making this assay suitable for clinical use. This proposed method is fast, requires fewer handling steps, without further post-PCR processing for HLA genotyping and provides $100 \%$ sensitivity and specificity.

\section{Materials and Methods}

\section{Study Population}

A total of 44 Egyptian patients with confirmed Chronic Hepatitis C (CHC) treated with peg-IFN plus ribavirin were enrolled in this study (28 males, 16 females; mean ages $36.45 \pm 11.18$ years; range from 21-63). None of the patients had received prior antiviral treatment. Before peg-IFN therapy, diagnosis of $\mathrm{CHC}$ was established on persistent ( $>6$ months) elevation of Alanine aminotransferase (ALT) concentration 1.5 times above the upper limit of normal, positive results of antibody to HCV testing, positive HCV RNA testing in serum and histological evidence of chronic hepatitis and earlier fibrosis stages (Metavir stage $\leq \mathrm{F} 2$ ). The Metavir scoring system described as follows: For activity, A0 is no histological activity, A1 mild activity, A2 moderate activity and A3 severe activity; for fibrosis, F0 is no fibrosis, F1 portal tract expansion by fibrosis, F2 less than $50 \%$ bridging fibrosis, F3 more than $50 \%$ bridging fibrosis without cirrhosis and F4 established cirrhosis (Shaker et al., 2013). They were followed from March 2012 to March 2014 at outpatient clinics of hepatology unit, Al-Ahrar Hospital (Zagazig, Egypt) under the supervision of the National Committee for the Control of Viral Hepatitis (NCCVH). Patients were negative for Hepatitis B surface Antigen (HBsAg), autoimmune hepatitis, antinuclear antibodies, Human Immunodeficiency Virus (HIV) and active schistosomiasis. HCV genotypes of the patients were taken from the patients' records.

The study protocol and informed consent were approved by the Ethical Committee of NCCVH.

\section{Study Design}

All patients were treated with subcutaneous injections of peg-IFN $\alpha-2 \mathrm{a}(180 \mu \mathrm{g} /$ week $)$ combined with orally given ribavirin (1000-1200 mg/day, body weight based) for 48 weeks. The presence of HCV RNA in the serum was tested at weeks $12,24,48$ and 72 by real-time PCR. Patients achieving SVR in terms of clearance of serum HCV RNA by real time PCR at the end of the therapy and for 6 months after the cessation of therapy were grouped as sustained responders (group 1). All other patients did not achieve SVR were classified as non-responders (group 2) (Dai et al., 2010).

\section{Real-Time PCR for Serum HCV RNA}

Serum HCV RNA was determined by standardized automated quantitative Polymerase Chain Reaction (PCR) (COBAS AmpliPrep/COBAS TaqMan HCV Test, Roche molecular system, USA). All steps were 
performed automatically including; sample preparation to isolate HCV RNA, reverse transcription of the target RNA to generate complementary DNA (cDNA) then automated simultaneous PCR amplification and detection of cleaved dual-labeled oligonucleotide detection probe specific to the target. Serum HCV RNA was expressed as International Units (IU) per $\mathrm{ml}$. The detection limit was from 15 to $6.90 \chi 10^{7} \mathrm{IU} / \mathrm{ml}$.

\section{HLA DRB1 Typing}

From both groups genomic DNA was extracted and purified from whole blood using PREP-RAPID GENETICS DNA Extraction Kit (DNA technology, Russia), according to the manufacturer's instructions. The supernatant containing isolated DNA was stored at $-20^{\circ} \mathrm{C}$ to be used for PCR. Genotyping of HLA class II alleles were performed at DRB1 regions using real-time PCR (DNA-Technology, Russia) which applies DTlite4 real-time thermal cycler, according to the manufacturer's instructions. Paraffin sealed PCR-mix $\mathrm{A}$ and $\mathrm{B}$ strips, included in the kit, contained primers, a fluorogenic locus-specific probe, master mix and internal control which were pre-aliquoted and frozen in the strips so that only Taq-polymerase solution and extracted DNA were added.

\section{Statistical Analysis}

All patients' data were tabulated and processed using Statistical Package for Social Sciences (SPSS) software 16.0 for Windows XP. Qualitative data were expressed in number and percent; they were compared using Chisquare test or Fischer's exact test when appropriate. Quantitative data were expressed in terms of mean and standard deviation. They were compared using Student's t-test. Odds Ratios (ORs) were calculated for different alleles, whenever a significant $P$ value in the distribution of a specific allele was observed. In all tests, $p$ value less than 0.05 was considered to be significant.

\section{Results}

Among the $44 \mathrm{CHC}$ patients, the mean pretreatment HCV RNA level was $575640 \pm 360260 \mathrm{IU} / \mathrm{ml}$, baseline ALT was minimally elevated (mean 1-1.5 times the Upper Limit of Normal (ULN) level) in 50\% and moderately elevated (mean $>1.5$ times ULN) in the other $50 \%$ of the patients. Thirty patients were infected by genotype $4(68.18 \%)$ while other genotypes 1,2 and 3 were present in $13.6,13.6$ and $4.5 \%$ of $\mathrm{CHC}$ patients respectively (Table 1).

Response to Combination Therapy with PEG-IFN $2 a$ and Ribavirin in CHC Patients

After PEG-INF/ribavirin therapy, 40.9\% (18/44) of patients achieved SVR and 59.1\% (26/44) were non responders. Comparison of the clinical, virological and laboratory factors between sustained responders and non-responders is shown in Table 1. The univariate analysis of clinical and virological factors showed that female sex, genotype 2, lower pretreatment HCV RNA level, higher ALT at $1^{\text {st }}$ week of therapy and lower $\mathrm{Hb}$ level at $4^{\text {th }}$ week and $12^{\text {th }}$ week were associated with a higher probability of sustained response with statistically significant difference for each $(\mathrm{p}<0.05)$. Ribavirin dose reduction was necessary in these $\mathrm{HCV}$ treatment related anaemic patients.

\section{HLA DRB1 Alleles and Response to Therapy in CHC Patients}

HLA DRB1 typing was performed in all patients (Table 2). It was demonstrated that HLA DRB1 *07 and HLA DRB $1 * 13$ were the most frequent alleles observed in $\mathrm{CHC}$ patients representing 31.8 and $36.4 \%$ respectively. The frequency of HLA DRB1 alleles in the sustained responders and non-responders were compared (Table 3). In univariate analysis, an increase in frequency $(\mathrm{p}<0.001)$ of HLA DRB1 $* 13$ was observed in sustained responders $(77.8 \% ; 95 \%$ confidence interval with an Odd Ratio (OR) of 42 (2.38-77.29)). On the other hand, DRB1*7 was significantly $(\mathrm{p}<0.01)$ more frequent in non responders $(53.8 \%)$.

\section{HLA DRB1 Alleles and Response to Therapy among CHC Patients with HCV Genotype 4}

Among the 18 patients with sustained response only 8 had HCV genotype 4 (44.5\%) whereas in non responders $\mathrm{HCV}$ genotype 4 was observed in 22 of 26 patients (84.6\%). Comparison of clinical, virological features, HLA DRB $1 * 07$ and $* 13$ frequency in patients infected by HCV genotype 4 according to response to therapy is shown in Table 4. Eight of the $22 \mathrm{CHC}$ patients with no response and $\mathrm{HCV}$ genotype 4 had the DRB1*07 allele $(36.4 \%)$ with its absence in sustained responders with HCV genotype $4(p<0.01)$. On the other hand 6 of 8 patients with sustained response and HCV genotype 4 had the DRB1 *13 allele $(75 \%) \quad(\mathrm{p}<0.001)$ with its absence in non responders.

In $\mathrm{HCV}$ genotype 4, like other $\mathrm{HCV}$ genotypes infected patients, easy fatigability was less frequent in sustained responders than non responders and female gender respond to therapy more frequently than male $(\mathrm{p}<0.05)$. In addition, in patients infected with $\mathrm{HCV}$ genotype 4, pretreatment serum HCV RNA level was significantly lower $(p<0.05)$ in the eight patients with sustained response as compared to 22 patients with no response. 
Awny Aly Abol-Ez Gawish et al. / American Journal of Immunology 201511 (3): 108.115 DOI: 10.3844/ajisp.2015.108.115

Table 1. The Clinical, virological and laboratory features of $44 \mathrm{CHC}$ patients according to response to therapy

\begin{tabular}{|c|c|c|}
\hline & Group I Sustained responders $(\mathrm{n}=18)$ & Group II Non responders $(\mathrm{n}=26)$ \\
\hline Male/Female & $6 / 12 *$ & $22 / 4$ \\
\hline Mean age (years $\pm \mathrm{SD}$ ) & $30.22 \pm 5.19$ & $40.77 \pm 12.30$ \\
\hline \multicolumn{3}{|l|}{ Symptoms (\%) } \\
\hline No & $16(88.9 \%)^{*}$ & $8(30.8 \%)$ \\
\hline Easy fatigability & $2(11.1 \%)^{*}$ & $10(38.5 \%)$ \\
\hline Abdominal pain & $0(0 \%)$ & $6(23.1 \%)$ \\
\hline Jaundice & $0(0 \%)$ & $2(7.7 \%)$ \\
\hline \multicolumn{3}{|l|}{$\mathrm{HB}(g m / d l):$} \\
\hline Base line Mean $\pm S D$ & $13.94 \pm 1.72$ & $14.39 \pm 1.67$ \\
\hline 4weeks Mean $\pm S D$ & $11.96 \pm 1.98^{*}$ & $13.82 \pm 1.75$ \\
\hline 12 weeks Mean $\pm S D$ & $8.94 \pm 1.87 * *$ & $13.40 \pm 1.92$ \\
\hline \multicolumn{3}{|l|}{$\operatorname{ALT}(\mathrm{U} / \mathrm{L}):$} \\
\hline \multicolumn{3}{|l|}{ Baseline: (\%) } \\
\hline Normal & $0(0 \%)$ & $0(0)$ \\
\hline Minimal elevated $a^{I}$ & $8(44.4 \%)$ & $14(53.8 \%)$ \\
\hline \multicolumn{3}{|l|}{$1^{S T}$ week: (\%) } \\
\hline Normal & $4(22.2 \%)^{*}$ & $8(30.8 \%)$ \\
\hline Minimal elevated & $0(0 \%)^{*}$ & $10(38.5 \%)$ \\
\hline $\begin{array}{l}\text { Moderately elevated } \\
4^{4^{h}} \text { week: (\%) }\end{array}$ & $14(77.8 \%)^{*}$ & $8(30.8 \%)$ \\
\hline Normal & $16(88.9 \%)$ & $20(76.9 \%)$ \\
\hline Minimal elevated & $2(11.1 \%)$ & $2(7.7 \%)$ \\
\hline Moderately elevated & $0(0 \%)$ & $4(15.4 \%)$ \\
\hline \multicolumn{3}{|l|}{ Genotype (N) } \\
\hline $1(6)$ & $2(11.1 \%)$ & $4(15.4 \%)$ \\
\hline $2(6)$ & $6(33.3 \%)^{*}$ & $0(0 \%)$ \\
\hline $3(2)$ & $2(11.1 \%)$ & $0(0 \%)$ \\
\hline $4(30)$ & $8(44.5 \%)^{*}$ & $22(84.6 \%)$ \\
\hline \multicolumn{3}{|l|}{$\begin{array}{l}\text { Viral load: } \\
(I U / m l)\end{array}$} \\
\hline Base line Mean $\pm S D$ & $273780 \pm 269545^{* *}$ & $784620 \pm 251085$ \\
\hline
\end{tabular}

$* \mathrm{p}<0.05$ significant

$* * \mathrm{p}<0.001$ highly significant

$a^{1}$ minimally elevated ALT level means 1-1.5 times the Upper Limit Of Normal (ULN) level (ULN $=33$ U/L for males and 24 U/L for females

$\mathrm{a}^{2}$ moderately elevated mean $>1.5$ times ULN.

Table 2. HLA class II (HLA DRB1) alleles of the all CHC patients

\begin{tabular}{lcr} 
& CHC patients $(n=44)$ & \\
Variable & No & \\
\hline Alleles: & & 13.6 \\
$D R B 1 * 01$ & 6 & 9.1 \\
$D R B 1 * 03$ & 4 & 4.5 \\
$D R B 1 * 04$ & 2 & 31.8 \\
$D R B 1 * 07$ & 14 & 9.1 \\
$D R B 1 * 08$ & 4 & 18.2 \\
$D R B 1 * 10$ & 8 & 22.7 \\
$D R B 1 * 11$ & 10 & 4.5 \\
$D R B 1 * 12$ & 2 & 36.4 \\
$D R B 1 * 13$ & 16 & 4.5 \\
$D R B 1 * 14$ & 2 & 13.6 \\
$D R B 1 * 15$ & 6 & \\
\hline
\end{tabular}


Table 3. Distribution of HLA DRB1 alleles and response to therapy in CHC patients

\begin{tabular}{|c|c|c|c|c|c|c|c|}
\hline & \multicolumn{2}{|c|}{$\begin{array}{l}\text { Group I (Sustained } \\
\text { responder) }(\mathrm{n}=18)\end{array}$} & \multicolumn{5}{|c|}{$\begin{array}{l}\text { Group II (Non-responder) } \\
(\mathrm{n}=26)\end{array}$} \\
\hline & No & $\%$ & No & $\%$ & $\chi^{2}$ & $\mathrm{p}$ & OR \\
\hline \multicolumn{8}{|l|}{ Alleles: } \\
\hline$D R B 1 * 01$ & 4 & 22.2 & 2 & 7.7 & 0.95 & 0.33 N.S & $3.43(0.18-17.72)$ \\
\hline$D R B 1 * 03$ & 2 & 11.1 & 2 & 7.7 & 0.08 & 0.78 N.S & $1.50(0.01-6.30)$ \\
\hline$D R B 1 * 04$ & 2 & 11.1 & 0 & 0.0 & 1.51 & 0.22 N.S & ----- \\
\hline$D R B 1 * 07$ & 0 & 0.0 & 14 & 53.8 & 7.11 & $0.01 *$ & -------- \\
\hline$D R B 1 * 08$ & 2 & 11.1 & 2 & 7.7 & 0.08 & 0.78 N.S & $1.50(0.01-6.30)$ \\
\hline$D R B 1 * 10$ & 2 & 11.1 & 6 & 23.1 & 0.51 & 0.47 N.S & $0.42(0.01-6.39)$ \\
\hline$D R B 1 * 11$ & 2 & 11.1 & 8 & 30.8 & 1.17 & 0.28 N.S & $0.28(0.01-3.93)$ \\
\hline$D R B 1 * 12$ & 0 & 0.0 & 2 & 7.7 & 0.73 & 0.39 N.S & - \\
\hline$D R B 1 * 13$ & 14 & 77.8 & 2 & 7.7 & 11.29 & $0.001^{* *}$ & $42(2.38-77.29)$ \\
\hline$D R B 1 * 14$ & 0 & 0.0 & 2 & 7.7 & 0.73 & 0.39 N.S & ---- \\
\hline$D R B 1 * 15$ & 2 & 11.1 & 4 & 15.4 & 0.08 & 0.77 N.S & $0.69(0.15-12.98)$ \\
\hline
\end{tabular}

OR: Odds Ratio

$* \mathrm{p}<0.05$ significant

$* * \mathrm{p}<0.001$ highly significant

Table 4. Comparison of clinical, virological features, HLA DRB $1 * 07$ and $* 13$ frequency in patients infected by HCV genotype 4 according to response to therapy

\begin{tabular}{lll}
\hline & Genotype 4 Sustained responders $(\mathrm{n}=8)$ & Genotype 4 Non responders $(\mathrm{n}=22)$ \\
\hline Male/Female & $2 / 6^{* *}$ & $18 / 4$ \\
Mean age (years $\pm \mathrm{SD})$ & $34.25 \pm 3.36$ & $39.82 \pm 12.37$ \\
Symptoms (\%) & & \\
No & $6(75 \%)$ & $8(36.4 \%)$ \\
Easy fatigability & $2(25 \%)^{*}$ & $10(45.5 \%)$ \\
Abdominal pain & $0(0 \%)$ & $4(18.1 \%)$ \\
Jaundice & $0(0 \%)$ & $0(0 \%)$ \\
HLA DRB1 type: & $0(0 \%)^{* *}$ & $8(36.4 \%)$ \\
HLA DRB1*07 & $6(75 \%)^{* *}$ & $0(0 \%)$ \\
HLA DRB1*13 & & \\
Viral load: & $369750 \pm 390188^{*}$ & $690910 \pm 320732$ \\
Base line Mean \pm SD & &
\end{tabular}

$* \mathrm{p}<0.05$ significant

$* * \mathrm{p}<0.001$ highly significant

\section{Discussion}

IFN-a is an effective therapy for CHC but only about $55 \%$ of patients can successfully clear the virus depending on virological factors and host factors including immunogenetic factors (Dai et al., 2010).

HLA class II genes are a crucial factor that regulates immune response through the presentation of viral antigens to CD4 T lymphocytes (Shiina et al., 2009). HLA alleles are highly polymorphic among different populations which give variation in immune response (Timm et al., 2007).

In the present study we investigated the possible association between HLA class II DRB1 alleles and response to PEG-IFN/ribavirin therapy in patients with $\mathrm{CHC}$.

In the present study, HLA DRB $1 * 07$ and HLA DRB $1 * 13$ representing 31.8 and $36.4 \%$ of $\mathrm{CHC}$ patients respectively were the most prevalent alleles demonstrated. By comparing the frequencies of HLA
DRB1 alleles between patients who responded and those who did not respond to combination treatment, HLA DRB1 *13 allele showed a significant association with SVR while HLA DRB1 $* 07$ allele showed a significant association with non responded patients.

Regarding the association of HLA DRB1 alleles and response to combination treatment, $\mathrm{CHC}$ patients with genotype 4 showed the same result.

Effective presentation of viral antigens to CD4+ T cells by HLA class II molecules is the key regulation of optimum immune response against viral infection. With the upregulated expression of immunogenetic molecules which enhances the immune response by IFN, the genetic variations at HLA loci with respect to antigen presentation might be a candidate related to response to IFN based therapy.

The association of HLA alleles with HCV infection in the Egyptian population has been addressed in several studies. Our result concerning HLA DRB $1 * 13$ is in 
agreement with Shaker et al. (2013) who reported that $\mathrm{DRB} 1 * 1301, \quad \mathrm{DRB} 1 * 1361, \quad \mathrm{DRB} 1 * 1369, \quad \mathrm{DRB} 1 * 13$ alleles to be significantly more frequent in responders than in non responders. Concerning our results of HLA DRB $1 * 07$, we agree with Zekri et al. (2005) who showed that HLA class II allele DR* 07 was significantly encountered in $\mathrm{HCV}$ positive family members than negative members. Furthermore, our results are concordant with those of Hendy et al. (2011), who demonstrated DRB $1 * 7$ and DQB $1 * 02$ alleles to be associated with viral persistence.

These findings were also supported by a cohort study on Pakistani HCV patients treated with IFN therapy which reported that HLA-DRB $1 * 07$ individually or in combination with HLA-DQB $1 * 02$ was associated with viral persistence, however unlike our results, HLADRB1*11 was found to be associated with viral clearance (Ali et al., 2010). In addition, in the Polish population, HLA DRB $1 * 07$ and DRB1*13 were more frequent in non-responders and responders to treatment respectively, but without statistical significance (Piekarska et al., 2002).

A great disagreement is noticed with Dincer et al. (2001) who demonstrated that patients not responding to treatment with interferon more frequently revealed the presence of DRB $1 * 13$ allele than among others.

In general, different studies in different populations had reported presence of different specific HLA alleles or significant haplotype to be correlated with response or no response to treatment. In Taiwan, HLA-DRB $1 * 15$ allele was positively correlated with a sustained response to IFN- $\alpha$ (Bruno et al., 2004). In Caucasian patients from Canada, DRB $1 * 0404$ allele was associated with response to treatment (De Re et al., 2010). In Turkish patients infected with HCV, HLA DRB1 *10 allele was associated with viral clearance (Ocal et al., 2014).

Meanwhile, other studies found no difference in distribution of HLA alleles between responders and non responders to antiviral therapy, for instance, in German, Knolle et al. (1998) have reported that, in patients suffering from chronic hepatitis $\mathrm{C}$ and treated with IFN$\alpha$, the pretreatment viral factors, not host factors, were significantly correlated with treatment response. Romero-Gomez et al. (2003) reported that in Spanish population, HLA class II showed no effect on response to interferon treatment.

Although our results coincided with other studies made in Egypt regarding association of HLA DRB1 *13 and HLA DRB1*07 with response to combined treatment of pegylated interferon and ribavirin, they were different from other studies in other populations which may due to the difference in the race, genetic background of the patients and treatment response.

Several pretreatment related features as younger age, female sex, in addition to clinical parameters including non-genotype 1 infection and lower levels of viremia have been currently reported to be associated with a better response (Dai et al., 2010).

In accordance with these previous reports, our study found that younger age; female sex, non-1 HCV genotype, particularly genotype 2 and low serum HCV RNA were associated with a sustained response.

Although $\mathrm{HCV}$ genotyping is an important predictor for the treatment response, no patient should be left without therapy on the basis of the genotype alone because the predictive value of $\mathrm{HCV}$ genotyping for interferon based therapy is only 55\% (Imran et al., 2013).

Complications of interferon/ribavirin therapy are so many. Anemia can be one of the most clinically significant side effects of therapy. Anemia is a dosedependent side-effect of ribavirin administration. The mean $\mathrm{Hb}$ concentration was significantly different in two groups. A decrease of the mean hemoglobin concentration at $4^{\text {th }}$ week and $12^{\text {th }}$ week of therapy significantly associated with sustained virological response. Our results are supported by that of the results of Urbanek et al. (2013) who concluded that the decrease in $\mathrm{Hb}$ concentration may serve as an additional predictive factor of SVR in patients with chronic HCV infection under antiviral treatment and the most useful factors are a $\mathrm{Hb}$ decrease at $4^{\text {th }}$ week and $12^{\text {th }}$ week of therapy.

Among the most sensitive and widely used liver enzymes are the aminotransferases. ALT acts as a biomarker of hepatocyte injury and is associated with the progression of hepatic fibrosis (Ribeiro et al., 2003).

Most of responders in our study $(77.8 \%)$ showed a moderate elevation of ALT level at $1^{\text {st }}$ week of therapy when compared to its pretreatment value, followed by return to baseline or within normal ranges at the $4^{\text {th }}$ week. The elevated ALT level during therapy may be attributed to degenerative, apoptotic and necrotic changes in hepatocytes, probably a result of the cytotoxic effects of IFN, rather than to increased hepatitis activity (Fujimori et al., 2002).

Our result is in agreement with Ribeiro et al. (2003) who observed 4 patterns of ALT change during therapy; one of them was an initial increase of ALT level followed by a decrease in the long term therapy in approximately $50 \%$ of the studied patients. In most patients, this behavior was accompanied by a viral load drop of more than 1 log from baseline over the same period.

\section{Conclusion}

We are aware with the main limitation of this study, which is the relatively small number of cases because of the high cost of the test.

However we can conclude that certain HLA-DRB1 alleles may act as predictors for response to treatment in the Egyptian population e.g. HLA DRB $1 * 07$ and HLA 
DRB1 *13. This is important for disease management and deciding which patient would most likely benefit from IFN therapy and which would not.

\section{Recommendation}

In Egypt, there is still a struggle for approving the new direct-acting inhibitors of HCV that will be used in combination with interferon or without the application of interferon, so further future studies of factors that may predict the treatment outcome of the new combinational therapies are required. HLA typing with the same combination of therapy with added Sofosbuvir as a new strategy started recently in Egypt.

\section{Acknowledgement}

Deep thanks to Dr. Ayman Marei, Professor of medical microbiology and immunology, faculty of medicine, Zagazig University, for supplying us with DTlite 4 real time thermal cycler used in this study.

\section{Funding Information}

This study was funded by Medical Microbiology and Immunology Department, Faculty of Medicine, Zagazig University.

\section{Author's Contributions}

Awny Aly Abol-Ez Gawish: Designed the research plan and organized the study.

Nahla Abd El-Hamid Mohammed and Dr.Rasha Adel Sayed Ahmed Hussein: Participated in all experiments, coordinated the data-analysis and contributed to the writing of the manuscript.

Elsaid Galal El-Badrawy: Participated in proper selection of the study cases, collection of clinical samples, clinical data, revision of the manuscript.

\section{Ethics}

This article is original and contains unpublished material. The corresponding author confirms that all of the other authors have read and approved the manuscript and no ethical issues involved.

\section{References}

Alberti, A. and L. Benvegnù, 2003. Management of hepatitis C. J. Hepatol., 1: S104-S118. DOI: $10.1016 / \mathrm{S} 0168-8278(03) 00008-4$

Ali, L., A. Mansoor and N. Ahmad, 2010. Patient HLA$\mathrm{DRB}^{*}$ and -DQB1* allele and haplotype association with hepatitis $\mathrm{C}$ virus persistence and clearance. J. General Virol., 91: 1931-1938.

DOI: 10.1099/vir.0.018119-0
Bhatti, Z. and C.S. Berenson, 2007. Adult systemic cat scratch disease associated with therapy for hepatitis C. BMC Infect. Dis., 7: 8-8. DOI: $10.1186 / 1471-2334-7-8$

Bruno, R., P. Sacchi, L. Maiocchi, C. Zocchetti and G. Filice, 2004. Host factors affecting the outcome of treatment of hepatitis C. Rev. Gastroenterol. Disorders, 4: S3-S7. PMID: 15184818

Dai, C.Y., J.F. Huang, M.Y. Hsieh, N.J. Hou and Z.Y. Lin et al., 2009. Insulin resistance predicts response to peginterferon-alpha/ribavirin combination therapy in chronic hepatitis C patients. J. Hepatol., 50: 712-718. DOI: 10.1016/j.jhep.2008.12.017

Dai, C., W. Chuang, M. Hsieh, J. Huang and Y.Y. Lin et al., 2010. Human leukocyte antigen alleles and the response to pegylated interferon/ribavirin therapy in chronic hepatitis C patients. Antiviral Res., 85: 396-402. DOI: 10.1016/j.antiviral.2009.11.006

De Re, V., L. Caggiari and G. Monti, 2010. HLA DRDQ combination associated with the increased risk of developing human HCV positive non-Hodgkin's lymphoma is related to the type II mixed cryoglobulinemia. Tissue Antigens, 75: 127-135. DOI: 10.1111/j.1399-0039.2009.01414.x

Dincer, D., F. Besisik, F. Oguz, M.S. Sever and S. Kaymakoglu et al., 2001. Genes of major histocompatibility complex class II influence chronic $\mathrm{C}$ hepatitis treatment with interferon in hemodialysis patients. Int. J. Artif. Organs, 24: 212-214. PMID: 11394702

Elkady, A., Y. Tanaka and F. Kurbanov, 2009. Genetic variability of hepatitis $\mathrm{C}$ virus in south Egypt and its possible clinical implication. J. Med. Virol., 81: 1015-1023. DOI: 10.1002/jmv.21492

El Makhzangy, H., G. Esmat and M. Said, 2009. Response to pegylated interferon alfa- $2 \mathrm{a}$ and ribavirin in chronic hepatitis C genotype 4 . J. Med. Virol., 81: 1576-1583. DOI: 10.1002/jmv.21570

Fujimori, K., S. Mochida, A. Matsui, A. Ohno and K. Fujiwara, 2002. Possible mechanisms of elevation of serum transaminase levels during interferon- $\beta$ therapy in chronic hepatitis $\mathrm{C}$ patients. J. Gastroenterol., 37: 40-46. DOI: $10.1007 / \mathrm{s} 535-002-8131-9$

Hendy, O., E. Abd Elmonean and M. Allamet, 2011. Human Leukocyte Antigen class II, (HLA-II) alleles and interferon response in $\mathrm{HCV}$ chronically infected Egyptian patients. Int. Res. J. Microbiol., 2: 133-140.

Imran, M., S. Manzoor, J. Ashraf, M. Khalid and M. Tariq et al., 2013. Role of viral and host factors in interferon based therapy of hepatitis $\mathrm{C}$ virus infection. Virol. J., 10: 299-299.

DOI: $10.1186 / 1743-422 \mathrm{X}-10-299$ 
Knolle, P.A., S. Kremp, T. Hohler, F. Krummenauer and P. Schirmacher et al., 1998. Viral and host factors in the prediction of response to interferon- $\alpha$ therapy in chronic hepatitis $\mathrm{C}$ after long-term follow-up. J. Viral Hepatitis 5: 399-406. DOI: $10.1046 / \mathrm{j} .1365-2893.1998 .00127 . \mathrm{x}$

Maylin, S., M. Martinot-Peignoux and R. Moucari, 2008. Eradication of hepatitis $\mathrm{C}$ virus in patients successfully treated for chronic hepatitis C. Gastroenterology, 135: 821-829. DOI: 10.1053/j.gastro.2008.05.044

Mosaad, Y.M., R.E. Farag, M.M. Arafa, S. Eletreby and H.A. El-Alfy et al., 2010. Association of Human Leucocyte Antigen Class I (HLA-A and HLA-B) with chronic hepatitis $\mathrm{c}$ virus infection in Egyptian patients. Scandinavian J. Immunol., 72: 548-553. DOI: $10.1111 /$ j.1365-3083.2010.02468.x

NCCVH, 2014. New guidelines for the management of HCV. National Committee for the Control of Viral Hepatitis.

Ocal, S., H. Selcuk, M. Korkmaz, R. Altun and A.E. Yildirim et al., 2014. Effect of HLA on hepatitis C virus clearance and persistence in anti-HCV-positive end-stage renal disease patients. Saudi J. Gastroenterol., 20: 175-181. DOI: $10.4103 / 1319-3767.133007$

Piekarska, A., G. Woszczek, M. Sidorkiewicz and J. Kuydowicz, 2002. HLA class II alleles and response to hepatitis $\mathrm{C}$ treatment with interferon alpha2b. Przeglad Epidemiologiczny, 56: 123-128. PMID: 12150055

Ribeiro, R.M., J. Layden-Almer, K.A. Powers, T.J. Layden and A.S. Perelson, 2003. Dynamics of alanine aminotransferase during Hepatitis $\mathrm{C}$ virus treatment. Hepatology, 38: 509-517. DOI: $10.1053 /$ jhep.2003.50344

Romero-Gomez, M., M.F. Gonzalez-Escribano, B. Torres, N. Barroso and M.A. Montes-Cano et al., 2003. HLA class I B44 is associated with sustained response to interferon + ribavirin therapy in patients with chronic hepatitis $\mathrm{C}$ combination therapy for HCV. Am. J. Gastroenterol., 98: 1621-1626.

DOI: $10.1111 / \mathrm{j} .1572-0241.2003 .07537 . \mathrm{x}$
Shaheen, N.M.H., A.R. Soliman, S.O. El-Khashab and M.O.F. Hanna, 2013. HLA DRB1 alleles and hepatitis $\mathrm{C}$ virus infection in chronic kidney disease patients. Renal Failure, 35: 386-390. DOI: $10.3109 / 0886022 X .2012 .761038$

Shaker, O., H. Bassiony, M. El Raziky, S.S. El-Kamary and G. Esmat et al., 2013. Human Leukocyte Antigen Class II Alleles (DQB1 and DRB1) as Predictors for Response to Interferon Therapy in HCV Genotype 4. Mediators Inflammat., 2013: 392746-392746. PMID: 23576852

Shiina, T., K. Hosomichi, H. Inoko and J.K. Kulski, 2009. The HLA genomic loci map: expression, interaction, diversity and disease. J. Human Genet., 54: 15-39. DOI: 10.1038/jhg.2008.5

Timm, J., B. Li, M.G. Daniels, T. Bhattacharya and L.L. Reyor et al., 2007. Human leukocyte antigenassociated sequence polymorphisms in hepatitis $\mathrm{C}$ virus reveal reproducible immune responses and constraints on viral evolution. Hepatology, 46: 339-349. DOI: 10.1002/hep.21702

Urbanek, P., M. Kreidlova, L. Dusek, R. Bruha and Z. Marecek et al., 2013. Anemia as a predictor of response to antiviral therapy in chronic hepatitis $\mathrm{C}$. Bratisl Lek Listy, 114: 213-217. DOI: 10.4149/bll_2013_044

Yosry, A., R. Fouad, S. Mahmoud, M. El-Raziky and A. El-Hennawy et al., 2011. The association of HLA class II DR B1 alleles with $\mathrm{HCV}$ infection in Egyptian children. Arab J. Gastroenterol., 12: 25-28. DOI: 10.1016/j.ajg.2011.01.007

Zekri, A.R., H.A. El-Mahallawy and A. Hassan, 2005. HLA alleles in Egyptian HCV genotype-4 carriers. Egypt J. Immunol., 12: 77-86. PMID: 16734142 